\title{
Qualidade microbiológica de leite cru produzido em cinco municípios do Estado do Rio Grande do Sul, Brasil
}

\author{
Microbiological quality of raw milk produced in five counties in Rio Grande do Sul state, Brazil \\ Cristiane da Rosa Moraes ${ }^{1}$, Alexandre Meneghello Fuentefria ${ }^{1}$, Cristina Bergman \\ Zaffari $^{1}$, Márcia Conte ${ }^{2}$, J osé Pedro Abatti Vianna Rocha ${ }^{3}$, Andréia Spanamberg ${ }^{3}$, \\ Patrícia Valente ${ }^{1,4}$, Gertrudes Corção $^{1,4} \&$ Marisa da Costa ${ }^{1,4}$
}

\begin{abstract}
RESUMO
O leite pode ser considerado um bom meio de cultura para o crescimento de microrganismos. Estes microrganismos podem contaminar o homem através da ingestão de leite cru, influenciar no tipo de processamento a ser utilizado e interferir na qualidade deste produto e seus derivados. Propriedades leiteiras de cinco municípios no estado do Rio Grande do Sul, Brasil, foram examinadas para determinar a qualidade microbiológica do leite produzido. Foi verificada a presença de coliformes totais, fecais e Salmonella sp. Foi realizada, também, a contagem de bactérias mesófilas, psicrotróficas e de leveduras. Dentre 42 propriedades, 41 apresentaram coliformes totais no leite. Não foi observada diferença significativa entre os tipos de ordenha e os diferentes métodos de resfriamento durante o armazenamento. Somente oito propriedades apresentaram coliformes fecais e confirmação de Escherichia coli, evidenciando falhas nos procedimentos higiênicos durante a ordenha ou armazenamento. Não foi detectada a presença de Salmonella sp. nas amostras, confirmando sua baixa prevalência no leite. Todas as 12 propriedades testadas quanto à presença de bactérias mesófilas e psicrotróficas apresentaram contagens superiores ou igual a 4 log.ufc.mL ${ }^{-1}$. Foi observada a presença de leveduras em 32 das 34 propriedades testadas com contagens variando entre 1,52 e acima de $4 \log$.ufc.mL $L^{-1}$. O número elevado de microrganismos observado no leite cru não interferiu na diminuição destes pela pasteurização e, possivelmente, se produzissem enzimas termoestáveis, estas não afetariam a qualidade do leite pasteurizado, que possui tempo de validade restrito. Porém estas enzimas poderiam afetar a qualidade de produtos derivados a partir deste leite (longa vida, queijos, etc.) devido ao maior período de contato destas enzimas e seus substratos.
\end{abstract}

Descritores: qualidade microbiológica, bactérias, leveduras, leite cru, pasteurização.

\section{ABSTRACT}

Milk can be considered as a good culture medium for the growth of microorganisms. These microorganisms can contaminate humans through the ingestion of raw milk, determine the type of product for which milk is to be used and compromise the quality and safety of milk and its derivatives. Dairy farms in five counties of Rio Grande do Sul state, Brazil, were examined to determine the microbiological quality of raw milk. The presence of total, fecal coliforms and Salmonella sp. were analyzed, as well as mesophiles, psychrotrophic bacteria, and yeasts. Among 42 farms tested, 41 presented total coliform bacteria in the milk samples. There was no significant difference between milking procedures and different refrigeration techniques during storage. Only eight farms presented fecal coliform bacteria and confirmation of $E$. coli, evidencing failure in hygienic procedures during milking or storage. Salmonella sp. was not detected in all samples, confirming its low prevalence in milk. All of the 12 farms analyzed for the presence of mesophilic and psychrotrophic bacteria presented counts superior or equal to $4 \log$.ufc.mL $\mathrm{L}^{-1}$. The presence of yeasts was observed in 32 of the 34 farms analyzed with counts ranging between 1,52 and over 4 log.ufc.mL $\mathrm{mL}^{-1}$. The high number of microorganisms observed in raw milk did not interfer with pasteurization, and even if thermostable enzymes were present, they would not modify the pasteurized milk quality, that has a short shelf life. However, these enzymes could change the quality of other processed milk products (UHT, cheese, etc.) due to the long contact time between these enzymes and their substrates.

Key words: microbiological quality, bacteria, yeast, raw milk, pasteurization. 


\section{INTRODUÇÃO}

A quantidade de microrganismos no leite influencia no tempo de prateleira e mesmo no tipo de produto para o qual o leite poderá ser utilizado [1]. Dois grupos de microrganismos podem ser destacados: (1) os não patogênicos, mas que alteram as propriedades do leite pela elevada acidez ou pela produção de enzimas termotolerantes, e (2) aqueles responsáveis por toxinfecções alimentares, que podem estar presentes no leite cru [9]. Assim, as condições higiênico-sanitárias devem ser monitoradas para garantir um produto seguro e de qualidade, sendo uma ferramenta para determinação dos pontos do processamento do produto que podem ser melhorados [8].

Neste estudo foi avaliada a qualidade higiênicosanitária do leite cru de mistura obtido de propriedades leiteiras, de cinco municípios diferentes do Estado do Rio Grande do Sul (RS), Brasil, pela pesquisa de microrganismos indicadores de qualidade sanitária (Escherichia coli) e patogênicos (Salmonella sp.), de microrganismos com capacidade de modificar as características do produto (bactérias mesófilas, psicrotróficas e leveduras) e a eficácia de sua pasteurização na indústria de beneficiamento.

\section{MATERIAIS E MÉTODOS}

\section{Amostragem}

Foram analisadas amostras provenientes de 42 propriedades leiteiras, com média de 11 animais em cada propriedade, localizadas em cinco municípios no Estado do Rio Grande do Sul, Brasil (Esteio, Gravataí, Glorinha, Sapucaia do Sul e Viamão). Após a homogeneização do leite, foi realizado o Teste de Alizarol (relativo à acidez) em cada propriedade e somente foram coletadas amostras com valores entre 14 e $18^{\circ}$ Dornic. Cada uma das propriedades foi visitada três vezes, entre os meses de outubro de 2003 e agosto de 2004. Foram coletados, de forma asséptica, $50 \mathrm{~mL}$ de leite cru em frascos esterilizados e transportados sob condições isotérmicas $\left( \pm 7^{\circ} \mathrm{C}\right)$ para serem imediatamente processados. Para cada dia de coleta $(n=8)$, também foram coletados $50 \mathrm{~mL}$ de leite, após terem sido pasteurizados, na indústria de beneficiamento. Durante as coletas foram observados os tipos de armazenamento e ordenha em cada propriedade.

\section{Contagem de bactérias e leveduras}

Após diluição de $25 \mathrm{~mL}$ de cada amostra em $225 \mathrm{~mL}$ de água peptonada tamponada (APT) 0,1\%, foram realizadas diluições decimais das amostras entre
$10^{-2}$ a $10^{-5}$. A partir destas diluições foram realizadas a contagem de: (1) coliformes totais e fecais, (2) bactérias mesófilas e psicrotróficas e (3) leveduras. Placas que continham entre 25 a 250 colônias foram selecionadas para a quantificação das colônias, sendo a contagem expressada em log.ufc. $\mathrm{mL}^{-1}$.

\section{Contagem de coliformes totais}

Para a contagem de coliformes totais foi utilizado o método proposto pelo USFDA (2002) [11], com algumas modificações. Alíquotas de $1 \mathrm{~mL}$ de cada diluição, citadas em 2.2, foram inoculadas em ágar Vermelho Violeta Bile Lactose ${ }^{3}$ (VRBA). Após solidificação, foi adicionada uma sobrecamada do mesmo meio e as placas foram incubadas a $37^{\circ} \mathrm{C}$ de 24 a 48 horas.

\section{Contagem de coliformes fecais e confirmação de Escherichia coli}

A presença de coliformes fecais foi confirmada semeando-se três colônias do VRBA, em tubos contendo $10 \mathrm{~mL}$ de caldo $\mathrm{EC}^{2}$. Foram considerados positivos os tubos que evidenciaram a presença de gás após 24-48 horas em banho-maria a $45^{\circ} \mathrm{C}$. A partir destes tubos, foram semeadas alíquotas em placas contendo ágar MacConkey $^{3}$ e incubadas por $24-48$ horas a $37^{\circ} \mathrm{C}$. As colônias circulares de cor rosa intenso foram selecionadas e submetidas a testes bioquímicos: indol, Vermelho de metila, Voges-Proskauer e citrato segundo recomendação do USFDA para a confirmação de E. coli [11].

\section{Detecção de Salmonella sp.}

Alíquotas de $25 \mathrm{~mL}$ de cada amostra foram diluídas em $225 \mathrm{~mL}$ de água peptonada tamponada (APT) $0,1 \%$, incubadas durante 24 horas a $37^{\circ} \mathrm{C}$. Volumes de 1 e $0,1 \mathrm{~mL}$ de cada amostra foram inoculados em tubos contendo 9 e 9,9 mL de Caldo Base Tetrationato $^{3}$ e Caldo Rappaport-Vassiliadis ${ }^{3}$, respectivamente, e incubados em banho-maria a $42^{\circ} \mathrm{C}$ por 24 horas. A partir dos caldos, foram semeadas alíquotas em ágar Xilose-Lisina-Desoxicolato ${ }^{3}$ e ágar Verde Brilhante Vermelho de Fenol Lactose Sacarose $^{3}$ e incubados a $37^{\circ} \mathrm{C}$ por $24 \mathrm{~h}$. Colônias presuntivas de Salmonella sp. foram inoculadas em tubos contendo ágar Ferro Tríplice Açúcar ${ }^{1}$ e ágar Ferro Lisina $^{1}$ e incubadas a $37^{\circ} \mathrm{C}$ por $24 \mathrm{~h}[5,12]$.

\section{Contagem de bactérias mesófilas e psicrotróficas}

A detecção foi realizada em 12 propriedades, de acordo com o método proposto por Silva et al. [8]. Para contagem dos microrganismos mesófilos, alíquotas de $1 \mathrm{~mL}$ das diluições, citadas em 2.2, foram inoculadas, em profundidade, em duplicata, em Ágar Padrão para 
Contagem $^{2}$ (PCA) e incubadas a $37^{\circ} \mathrm{C}$ por 48 horas. Para contagem dos microrganismos psicrotróficos, alíquotas de $0,1 \mathrm{~mL}$ das mesmas diluições foram inoculadas, em superfície, em PCA e incubadas a $7^{\circ} \mathrm{C}$ por 10 dias.

\section{Contagem de leveduras}

A contagem de leveduras foi realizada em 34 propriedades. Para o isolamento de leveduras, alíquotas de $0,1 \mathrm{~mL}$ das diluições, citadas em 2.2, foram inoculadas em triplicata em ágar YM acidificado (1\% glicose, $0,3 \%$ extrato de malte, $0,3 \%$ extrato de levedura, $0,5 \%$ peptona, $2 \%$ ágar, $\mathrm{pH} 4,5)$ ou ágar YEPG acidificado $(0,5 \%$ extrato de levedura, $2 \%$ glicose, $1 \%$ peptona, 2\% ágar, $\mathrm{pH} 4,5$ ) acrescidos de $400 \mathrm{mg} / \mathrm{L}$ de cloranfenicol. As placas foram incubadas a $22^{\circ} \mathrm{C}$ por até 4 dias.

\section{Análise estatística}

Todos os dados microbiológicos referentes aos coliformes totais, tipo de ordenha e armazenamento foram analisados usando valores na escala logarítmica. Análise da variância e Teste $\mathrm{t}$ foram estimados utilizan- do o software SPSS/PC versão 8 (SPSS Inc., Chicago, Illinois, EUA) pelo Laboratório de Estatística da UFRGS.

\section{RESULTADOS}

Foram examinadas 42 propriedades sendo 21 com ordenha manual e 21 com ordenha mecânica. Nas Tabelas 1 e 2 são apresentados os resultados da contagem de coliformes, bactérias mesófilas, bactérias psicrotróficas, leveduras e tipos de armazenamento.

Não foi isolada Salmonella sp. nas 42 propriedades. Das oito amostras de leite coletadas, após pasteurização, nenhuma apresentou crescimento de coliformes e Salmonella sp. Três destas amostras foram testadas quanto ao crescimento de bactérias mesófilas e psicrotróficas. Houve crescimento somente de bactérias psicrotróficas nas três amostras com contagem $\geq 4$ log.ufc. $\mathrm{mL}^{-1}$.

Das 34 propriedades testadas quanto à presença de leveduras no leite, 32 apresentaram presença destes microrganismos com contagens entre 1,52 e acima de 4 log.ufc. $\mathrm{mL}^{-1}$ (Tabelas 1 e 2).

\begin{tabular}{|c|c|c|c|c|c|}
\hline Propriedade & Armazenamento & Coliformes Totais & Mesófilas & Psicrotróficas & Leveduras \\
\hline $01,02,03$ & $-20^{\circ} \mathrm{C}$ & $\geq 4 \mathrm{e}$ & $\geq 4 \mathrm{e}$ & $\geq 4 \mathrm{e}$ & $\geq 4 \mathrm{e}$ \\
\hline 04 & $-20^{\circ} \mathrm{C}$ & $\geq 4 e$ & $\geq 4 \mathrm{e}$ & $\geq 4 \mathrm{e}$ & 1,52 \\
\hline 05 & $-20^{\circ} \mathrm{C}$ & $\geq 4 \mathrm{e}$ & 5,86 & 5,26 & 2,58 \\
\hline 06 & $-20^{\circ} \mathrm{C}$ & $\geq 4 \mathrm{e}$ & ND & ND & ND \\
\hline 07 & $-20^{\circ} \mathrm{C}$ & 4,02 & ND & ND & 2,52 \\
\hline 08 & $-20^{\circ} \mathrm{C}$ & 4,06 & ND & ND & 3,39 \\
\hline 09 & $-20^{\circ} \mathrm{C}$ & 4,85 & ND & ND & 2,08 \\
\hline 10 & $-20^{\circ} \mathrm{C}$ & 4,97 & ND & ND & 2,39 \\
\hline 11 & $-20^{\circ} \mathrm{C}$ & 5,02 & ND & ND & 3,08 \\
\hline 12 & $-20^{\circ} \mathrm{C}$ & 5,22 & ND & ND & 3,15 \\
\hline 13 & $-20^{\circ} \mathrm{C}$ & SC & ND & ND & $\geq 4 \mathrm{e}$ \\
\hline 14 & geladeira & 3,96 & ND & ND & 2,42 \\
\hline 15 & geladeira & 4,11 & ND & ND & 1,52 \\
\hline 16 & geladeira & 4,34 & 5,98 & 5,95 & $\geq 4 \mathrm{e}$ \\
\hline 17 & geladeira & 4,61 & ND & ND & 2,12 \\
\hline 18 & resfriador & $\geq 4 \mathrm{e}$ & $\geq 4 \mathrm{e}$ & 5,83 & $\geq 4 \mathrm{e}$ \\
\hline 19 & resfriador & 4,34 & ND & ND & 1,82 \\
\hline 20 & resfriador & 4,38 & ND & ND & 2,87 \\
\hline 21 & resfriador & 4,44 & ND & ND & ND \\
\hline
\end{tabular}




\begin{tabular}{|c|c|c|c|c|c|}
\hline Propriedade & Armazenamento & Coliformes Totais & Mesófilas & Psicrotróficas & Leveduras \\
\hline 22 & $-20^{\circ} \mathrm{C}$ & $\geq 4 \mathrm{e}$ & ND & ND & ND \\
\hline 23 & $-20^{\circ} \mathrm{C}$ & $\geq 4 \mathrm{e}$ & $\geq 4 \mathrm{e}$ & 5,15 & 2,74 \\
\hline 24,25 & $-20^{\circ} \mathrm{C}$ & $\geq 4 \mathrm{e}$ & $\geq 4 \mathrm{e}$ & $\geq 4 \mathrm{e}$ & $\geq 4 \mathrm{e}$ \\
\hline 26 & $-20^{\circ} \mathrm{C}$ & $\geq 4 \mathrm{e}$ & ND & ND & 2,25 \\
\hline 27 & $-20^{\circ} \mathrm{C}$ & $\geq 4 \mathrm{e}$ & ND & ND & ND \\
\hline 28 & $-20^{\circ} \mathrm{C}$ & 4,01 & ND & ND & 2,22 \\
\hline 29 & $-20^{\circ} \mathrm{C}$ & 4,60 & ND & ND & SC \\
\hline 30 & $-20^{\circ} \mathrm{C}$ & 4,63 & 5,27 & 5,42 & $\geq 4 \mathrm{e}$ \\
\hline 31 & $-20^{\circ} \mathrm{C}$ & 5,45 & ND & ND & 2,8 \\
\hline 32 & resfriador & 3,86 & $\geq 4 \mathrm{e}$ & 5,92 & SC \\
\hline 33 & resfriador & 4,12 & ND & ND & 2,54 \\
\hline 34 & resfriador & 4,29 & $\geq 4 \mathrm{e}$ & 4,82 & 2,73 \\
\hline 35 & resfriador & 4,56 & ND & ND & 2,77 \\
\hline 36 & resfriador & 4,68 & ND & ND & 2,62 \\
\hline 37 & resfriador & 4,7 & ND & ND & 2,70 \\
\hline 38 & resfriador & 5,19 & ND & ND & $\geq 4 \mathrm{e}$ \\
\hline 39 & resfriador & 5,48 & ND & ND & 2,34 \\
\hline 40 & expansão & $\geq 4 \mathrm{e}$ & $\geq 4 \mathrm{e}$ & $\geq 4 \mathrm{e}$ & $\geq 4 \mathrm{e}$ \\
\hline 41 & expansão & $\geq 4 \mathrm{e}$ & $\geq 4 \mathrm{e}$ & $\geq 4 \mathrm{e}$ & $\geq 4 \mathrm{e}$ \\
\hline 42 & expansão & 5,16 & ND & ND & ND \\
\hline
\end{tabular}

\section{DISCUSSÃO}

A contagem de coliformes totais variou entre 3,36 e 5,48 log.ufc.mL $\mathrm{mL}^{-1}$, referentes às propriedades 32 e 39, respectivamente. Todas as propriedades evidenciaram a presença de coliformes totais, exceto a propriedade 13 (Tabela 1). Não existe legislação determinando as quantidades de coliformes totais em leite cru. Comparando estes resultados com o limite máximo determinado para o leite pasteurizado, todas as propriedades apresentaram aproximadamente nove vezes o número de coliformes determinados pela legislação [2]. Não houve diferença significativa nas contagens de coliformes totais em relação ao tipo de ordenha (manual ou mecânica) e de armazenamento (congelador $-20^{\circ} \mathrm{C}$, geladeira, refrigeração ou tanque de expansão) utilizadas nas propriedades ( $>00,05)$.

Em oito propriedades, foram encontrados coliformes fecais em uma das três coletas realizadas, de- mostrando falhas de procedimentos de higiene durante a ordenha ou armazenamento.

A baixa prevalência de Salmonella sp. em leite bovino foi confirmada pela ausência deste gênero nas 42 propriedades. Estes dados estão em acordo com Ávila \& Gallo e Garrido et al. [1,4].

Entre as doze propriedades testadas quanto ao número de bactérias mesófilas, três ficaram dentro dos padrões exigidos pela legislação $\left(6 \log \cdot u f c \cdot \mathrm{mL}^{-1}\right)$ [2]. As demais propriedades apresentaram no mínimo, 4 log. ufc. $\mathrm{mL}^{-1}$, sendo que o número máximo exato não foi estimado por estar acima dos limites das diluições utilizadas. Segundo Soler et al. [10], contagens superiores a $10^{3}$ células por mililitro de leite cru ( 3 log.ufc. $\left.\mathrm{mL}^{-1}\right)$ podem ser responsáveis por defeitos na qualidade do leite pasteurizado. Entretanto, a ausência de bactérias mesófilas após a pasteurização, demonstrou que, apesar do núme- 
ro elevado destes microrganismos no leite cru, este tratamento térmico foi eficiente na eliminação destas bactérias. Porém, a influência nas suas características sensoriais não foi pesquisada.

A contagem de bactérias psicrotróficas nas doze propriedades testadas foi superior ou igual à $4 \log$.ufc. $\mathrm{mL}^{-1}$, não sendo possível estabelecer o número máximo de bactérias presentes. O limite máximo de psicrotróficos no leite cru que não interferiria na sua qualidade estaria entre 4 e 6 log.ufc.mL ${ }^{-1}[13,14]$. Zocche et al. [14] consideram que contagens acima de $4 \log$.ufc.mL ${ }^{-1}$ poderiam influenciar na qualidade do leite devido à ação de enzimas lipolíticas e proteolíticas produzidas pelos microrganismos e que permanecem ativas mesmo após o tratamento térmico. As psicrotróficas presentes no leite após pasteurização são provavelmente bactérias termotolerantes comuns no leite, que poderiam afetar o produto se o tempo de refrigeração e prateleira fosse superior aos estabelecidos pela legislação ou se utilizado na fabricação de outros produtos ou derivados que tenham um tempo de prateleira ou maturação prolongado.

A presença de leveduras no leite tem sido relatada mesmo após a pasteurização e geralmente não ultrapassa a concentração de 4 log.ufc.ml ${ }^{-1}$ no leite cru [6]. Dentre as 32 propriedades testadas, em 23 (72\%) foram encontradas concentrações dentro deste limite. Embora não exista legislação para estimar a presença de leveduras neste produto, a legislação brasileira determina um limite máximo de 3 log.ufc. $\mathrm{mL}^{-1}$ para queijos [3]. Doze propriedades (35\%) apresentaram contagem supe- rior a este limite. Várias leveduras possuem também a capacidade de degradar proteínas e lipídeos e são capazes de se reproduzirem em temperaturas entre 10 e $25^{\circ} \mathrm{C}$ [6]. A capacidade lítica de suas enzimas é semelhante a das enzimas bacterianas e provavelmente poderia influenciar nas características físico químicas do leite e seus derivados, principalmente daqueles produtos que têm um tempo mais prolongado de prateleira ou maturação [6,7].

\section{CONCLUSÕES}

Neste trabalho foi observado que a maioria das propriedades apresentou número elevado de microrganismos (bactérias e leveduras) e que em apenas $22 \%$ das propriedades foi constatada a presença de coliformes fecais, em uma das três coletas realizadas. Este número elevado de microrganismos não interferiu na pasteurização. Todavia, se produzissem enzimas termotolerantes, estas não afetariam a qualidade do leite pasteurizado, que possui tempo de validade restrito. Porém, tais enzimas poderiam afetar a qualidade deste leite se o mesmo fosse utilizado para outros produtos (longa vida, queijos, etc.) devido ao maior período de contato destas enzimas com seus substratos.

\section{NOTAS INFORMATIVAS}

${ }^{1}$ Biobrás, Montes Claros, Brasil.

${ }^{2}$ Difco, Le pont des Claix, França.

${ }^{3}$ Merck, Darmstadt, Alemanha.

${ }^{4}$ Oxoid, Hampshire, Inglaterra.

\section{REFERÊNCIAS}

1 Ávila C.R. \& Gallo C.R. 1996. Pesquisa de Salmonella spp. em leite cru, leite pasteurizado tipo Ce queijo "Minas Frescal" comercializados no município de Piracicaba - SP. Scientia Agricola. 53: 159-163.

2 Brasil. Secretaria de Defesa Agropecuária. Instrução Normativa n. 51. 2002. Ministério da Agricultura, Pecuária e Abastecimento. Secretaria de Defesa Agropecuária. Departamento de Inspeção de Produtos de Origem Animal (DIPOA). Serviço de Inspeção de Leite e Derivados. Instrução Normativa n. 51, de 18 de setembro de 2002. Regulamento Técnico de Identidade e Qualidade de Leite Cru Refrigerado, Anexo IV. Disponível em: <http://www.agricultura.gov.br>. Acessado em 09/2003.

3 Brasil. Secretaria de Vigilância Sanitária. R.D.C. N.12. 2001. Ministério da Saúde. Regulamento técnico. Princípios gerais para o estabelecimento de critérios e padrões microbiológicos para alimentos. Publicada em 02 de janeiro de 2001. Disponível em: 〈http://e-legis.br/leisref/public〉. Acessado em: 10/12/2002.

4 Garrido N.S., Morais J.M., Briganti R.C., Oliveira M.A., Bergamini S.A.V. \& Fávaro R.M.D. 2001. Avaliação da qualidade físico-química e microbiológica de leite pasteurizado proveniente de mini e micro-usinas de beneficiamento da região de Ribeirão Preto/SP. Revista do Instituto Adolfo Lutz. 2: 141-146.

5 MacFaddin J.P. \& Lippincott P. 2001. Biochemical tests for identification of medical bacteria. 3rd edn. Baltimore: Lippincott Willians \& Wilkins, 912p.

6 Roostita R. \& Fleer G.H. 1996. Growth of yeast in milk and associated changes to milk composition. International Journal of Food Microbiology. 31: 205-219. 
Moraes C.R., Fuentefria A.M.,Zaffari C.B., Conte M., Rocha J.P.A.V., Spanamberg A., Valente P., Corção G. \& Costa M. 2005. Qualidade microbiológica de leite cru produzido em cinco municípios...

7 Spanamberg A., Hartfelder C., Fuentefria A. \& Valente P. 2004. Diversity enzyme production by yeasts isolated from raw milk in Southern Brazil. Acta Scientiae Veterinariae. 32: 195-199.

8 Silva N., Junqueira V.C.A. \& Silveira N.F.A. 1997. Manual de métodos de análise microbiológica de alimentos. São Paulo: Varela, 317p.

9 Silveira N.V.V., Sakuma H., Duarte M., Rodas M.A.B, Saruwtari J.H. \& Chicoural E.L. 1989. Avaliação das condições físico-químicas e microbiológicas do leite pasteurizado consumindo na cidade de São Paulo. Revista do Instituo Adolfo Lutz. 49: $19-25$.

10 Soler A., Ponsell C., De Paz M. \& Nuñez M. 1995. The microbiological quality of milk produced in the Balearic Islands. International Dairy Journal. 5: 69-74.

11 United States Food and Drug Adminstration. 2002. Center for Food Safety \& Applied Nutrition. Bacteriological Analytical Manual Online. Enumeration of Escherichia coli and the coliform bacteria, 10p. Disponível em: 〈http://www.cfsan.fda.gov>. Acessado em 09/2003.

12 United States Food and Drug Adminstration. 2003. Center for Food Safety \& Applied Nutrition. Bacteriological Analytical Manual Online. Salmonella, 13p. Disponível em: <http://www.cfsan.fda.gov〉. Acessado em 04/2003.

13 Wessels D., Jooste P.J. \& Mostert J.F. 1989. Psychrotrophic, proteolitic and lipolitic properties of Enterobacteriaceae isolated from milk and dairy products. International Journal of Food Microbiology. 9: 79-83.

14 Zocche F., Bersot L.S., Barcellos V.C., Paranhos J.K., Rosa S.T.M. \& Raymundo N.K. 2002. Qualidade microbiológica e físico-química do leite pasteurizado produzido na região oeste do Paraná. Archives of Veterinary Science. 7: 59-67. 